\title{
Selection of Functions of the First Degree for Forecasting the Aggregate Bituminous Coal Size Characteristics
}

\author{
Vladimir Udovitsky \\ Department of Mineral Processing \\ T.F. Gorbachev Kuzbass State \\ Technical University \\ Kemerovo, Russian Federation \\ uvi@kuzstu.ru
}

\author{
Vladimir Kandinsky \\ Department of Mineral Processing T.F. \\ Gorbachev Kuzbass State Technical \\ University \\ Kemerovo, Russian Federation \\ uvi@kuzstu.ru
}

\begin{abstract}
The study considers sixteen functions of the first degree that were used for the analytical presentation of the aggregate size characteristics by "plus" of the Kuznetsk basin coal in the size range from 0 to $300 \mathrm{~mm}$. The computational experiment was carried out for 500 aggregate coal size characteristics. The parameters of the functions were determined by the known method of least squares. When required, the formulas were reduced to a linear form. To solve systems of linear algebraic equations, the Cramer method was used in Excel (using the built-in function MDETERM () for calculating matrix determinants), Gauss method in the TurboPascal (reduction of matrices to a triangular form). The quality of the approximations was estimated by the value of the standard deviation between experimental and calculated values of the total yields (ash content) of the size classes. To carry out the computational experiment in TurboPascal, computer programs Gran16_V.pas have been developed - to calculate the total yields of classes and Gran16_A.pas for calculating the ash content of the same classes. It is established that the Pogosov formula is the best in comparison with the others, including, with the well-known functions of Rosin-Rammler and GodenAndreev.
\end{abstract}

Keywords-cumulative size characteristics, approximation, the Cramer method, the Gauss method, approximating functions

\section{INTRODUCTION}

The grain-size distribution of minerals can be depicted graphically in the form of size performance curve, both partial and total. For coal, the characteristic is often plotted by "plus", in this case, the total values of the yields of all size classes that are larger than the given size of the sieve holes are plotted along the ordinate axis. The aggregate characteristics can be built also by "minus". Then the total yields of the classes indicate the amount of material that is less than the specified size of the sieve holes.

The size distribution can also be presented in analytical form. Many researchers have established that the grain size distribution by size makes it possible to assume the regularity of such a distribution, despite the difference in physical properties of minerals [1-10].

\section{MATERIALS AND METHODS}

The works of B.A. Zemlyakov presented the most complete review of the results of studies related to the patterns of particle distribution by size classes in the products of crushing and grinding.

The analytical dependence between the grain size of the product and its yield was first proposed in 1916 by A.O. Gates [1], who found that the cumulative characteristics of products had a hyperbolic form. This allowed us to describe the regularities of grinding in the form of equation

$$
y^{a_{0}}=a_{1} x,(1)
$$

Where $y$-total screen residue; $x$ - grain size; $a_{0}, a_{1}$ - here and hereinafter function parameters.

A.M. Gaudin [2], having studied a large number of experimental data on the grain size distribution of the crushing and grinding products, in 1926 obtained graphs of the characteristics described by the function

$$
y=a_{0} x^{a_{1}},(2)
$$

Where $y$ - sizes yield by weight; $x$ - the size of the sieve hole, on which the grains of this size remain.

S.E. Andreev applied the Gaudin equation to predict the mass cumulative characteristic by "minus". Further on, the function (2) became known as the Gaudin-Andreev equation.

P. Rosin and E. Rammler [3-6] (1932) studied the sieve composition of the grinding products and plotted their distribution curves. Analyzing the data of their experiments, P. Rosin, E. Rammler, and D. Richter [7] noted that in the $\ln (\ln (100 / y)), \ln (\mathrm{x})$ coordinate system, most experimental points lay on one straight line, the equation of which had the form $\ln (\ln (100 / \mathrm{y}))=\ln (\mathrm{a} 0)+a_{1} \cdot \ln (x)$, hence

$$
y=100 / \exp \left(a_{0} \cdot x^{a_{1}}\right),(3)
$$

where $y$-total screen residue, $\% ; x$ - the size of the sieve hole, $\mathrm{mm}$.

P. Roller [8] (1941) proposed expressing the dependence of mass yields on the particle size in the form of the formula

$$
y=\frac{a_{0} \sqrt{x}}{\exp \left(a_{1} / x\right)},(4)
$$

where $y$ - mass cumulative product yield by "minus". 
N.K. Beloglazov (1956), by transforming the RozinRammler equation (3), obtained the equation for the characteristic of the size of grinding products of monomineral ores by "minus"

$$
y=2 a_{0} x^{a_{1}} /\left(1+a_{0} x^{a_{1}}\right),(5)
$$

where $x$-product grain size, $y$ - mass cumulative yield by "minus".

A.M. Pogosov (1960) tried to extend the range of the actual size of the material described by the Beloglazov equation (5) by replacing the coefficient "2" by "1". He proposed the following formula

$$
y=1 a_{0} x^{a_{1}} /\left(1+a_{0} x^{a_{1}}\right),(6)
$$

where $x$-product grain size; $y$ - total yield by "minus".

The application of the Schuhmann equation is known as well [9]

$$
y=\left(x / a_{0}\right)^{a_{1}},(7)
$$

where $y$ - total product yield of the size smaller than the sieve size $x$.

\section{INITIAL DATA}

In this paper, sixteen functions presented in Table 1 are used to predict the total characteristics of bituminous coal particle size:

- (1) to (7) - known formulas: Gates (1), Gaudin-Andreev (2), Rosin-Rammler (3), Roller (4), Beloglazov (5), Pogosov (6) and Schuhmann (7);

- (8) to (16) - functions that can be used to approximate the total characteristics

TABLE 1. FORMULAS FOR FUNCTION OF THE FIRST DEGREE

\begin{tabular}{|c|c|c|c|}
\hline 1 & $y^{a_{0}}=a_{1} x$ & 9 & $y=x^{a_{0}+a_{1} x}$ \\
\hline 2 & $y=a_{0} x^{a_{1}}$ & 10 & $y=a_{0}+a_{1} x$ \\
\hline 3 & $y=100 / \exp \left(a_{0} \cdot x^{a_{1}}\right)$ & 11 & $y=a_{0} x+a_{1} / x$ \\
\hline 4 & $y=\frac{a_{0} \sqrt{x}}{\exp \left(a_{1} / x\right)}$ & 12 & $y=a_{0}+a_{1} / x$ \\
\hline 5 & $y=200 a_{0} x^{a_{1}} /\left(1+a_{0} x^{a_{1}}\right)$ & 13 & $y=100 /\left(a_{0}+a_{1} x\right)$ \\
\hline 6 & $y=100 a_{0} x^{a_{1}} /\left(1+a_{0} x^{a_{1}}\right)$ & 14 & $y=100 x /\left(a_{0} x+a_{1}\right)$ \\
\hline 7 & $y=\left(x / a_{0}\right)^{a_{1}}$ & 15 & $y=a_{0}+a_{1} \ln (x)$ \\
\hline 8 & $y=100 a_{0} x /\left(1+a_{1} x^{2}\right)$ & 16 & $y=\exp \left(a_{0}+a_{1} x\right)$ \\
\hline
\end{tabular}

The experimental values of the yields and ash content of the classes are taken from the materials of the studies carried out by the SibNII-Ugleobogascheniye Institute. As a result of the testing, the number of grain-size classes was from 8 to 14 . The maximum "plus" class size ranged from 300 to $25 \mathrm{~mm}$, the minimum - $0.05 \mathrm{~mm}$.

In the graphical or analytical presentation of the grain-size distribution characteristics, the values of the total "plus" yields are expressed as percentage, that is why the value of the coefficients in formulas:

- (5) - is taken as equal to ' 200 ' instead of ' 2 ';

- (6), (13) - ' 100 ' instead of 1 .

\section{MATHEMATICAL MODEL}

The parameters of the functions were determined by the known method of least squares. In this case, the functions must be linear. This condition was matched by four approximations, the numbers of which are: (10), (11), (12) and (15). The remaining formulas were linearized.

An example of linearization and search for parameters of function (6):

$$
y=100 a_{0} x^{a_{1}} /\left(1+a_{0} x^{a_{1}}\right),
$$

Let us linearize the function

$$
\begin{gathered}
y+y a_{0} x^{a 1}=100 a_{0} x^{a 1}, \\
y=a_{0} x^{a 1}(100-y), \\
y /(100-y)=a_{0} x^{a 1}, \\
\ln (y /(100-y))=\ln \left(a_{0}\right)+a_{1} \ln (x),
\end{gathered}
$$

Enter designation $c=\ln \left(a_{0}\right)$.

According to the method of least squares, we select the parameters of the function $\mathrm{c}$ and $a_{1}$ so as to ensure a minimum of the sum of the squared deviations between the experimental and the calculated values of the function

$$
U\left(c, a_{1}\right)=1 / n \Sigma\left(c+a_{1} \ln \left(x_{i}\right)-\ln \left(y_{i} /\left(100-y_{i}\right)\right)^{2},\right.
$$

We differentiate by $c$ and $a_{1}$

$\partial U / \partial c=2 \cdot 1 / n \Sigma\left(c+a_{1} \ln \left(x_{i}\right)-\ln \left(y_{i} /\left(100-y_{i}\right)\right) \cdot 1=0\right.$,

$\partial U / \partial a_{1}=2 \cdot 1 / n \Sigma\left(c+a_{1} \ln \left(x_{i}\right)-\ln \left(y_{i} /\left(100-y_{i}\right)\right) \cdot \ln \left(x_{i}\right)=0\right.$,

And obtain the system

$c+a_{1} 1 / n \Sigma \ln \left(x_{i}\right)=1 / n \Sigma \ln \left(y_{i} /\left(100-y_{i}\right)\right)=0$,

c $1 / n \sum \ln \left(x_{i}\right)+a_{1} 1 / n \sum \ln ^{2}\left(x_{i}\right)=1 / n \sum \ln \left(x_{i}\right) \ln \left(y_{i} /\left(100-y_{i}\right)\right)=0$.

We enter the notations:

$S_{0}=1, S_{1}=1 / n \Sigma \ln \left(x_{i}\right), S_{2}=1 / n \Sigma \ln ^{2}\left(x_{i}\right)$,

$B{ }_{0}=1 / n \sum \ln \left(y_{i} /\left(100-y_{i}\right)\right), B{ }_{1}=1 / n \Sigma \ln \left(x_{i}\right) \ln \left(y_{i} /\left(100-y_{i}\right)\right)$,

And reduce the system to the form

$$
\begin{aligned}
& c S_{0}+a_{1} S_{1}=B_{0} \\
& c S_{1}+a_{1} S_{2}=B_{1} .
\end{aligned}
$$

After that, we find the coefficient

$$
a_{0}=\exp (c) \text {. }
$$

The solution of a separate system of linear algebraic equations was carried out using the well-known Cramer formulas with Excel spreadsheets and the built-in MDETERM function MDETERM().

$$
X=\left(\begin{array}{c}
\frac{\operatorname{det} A_{1}}{\operatorname{det} A} \\
\frac{\operatorname{det} A_{2}}{\operatorname{det} A} \\
\cdots \cdots \cdots . . . \\
\frac{\operatorname{det} A_{n}}{\operatorname{det} A}
\end{array}\right),
$$

Where det $A=|A|$-determinant of the matrix of the system (the main determinant), $\operatorname{det} A_{i}=\left|A_{i}\right|(i=1,2, \ldots, n)$ are the determinants of the matrices $\mathrm{Ai}$ (auxiliary determinants) that are obtained from A by replacing the i-th column to the column of free terms B.

In solving several systems of linear algebraic equations, the Gauss method was used (reduction of matrices to triangular form) [10].

To implement the method, the Gauss.pas procedure is developed in the programming environment of TurboPascal.

Procedure text:

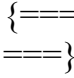


Procedure Gauss; \{Solution of linear equations systems by the Gauss method

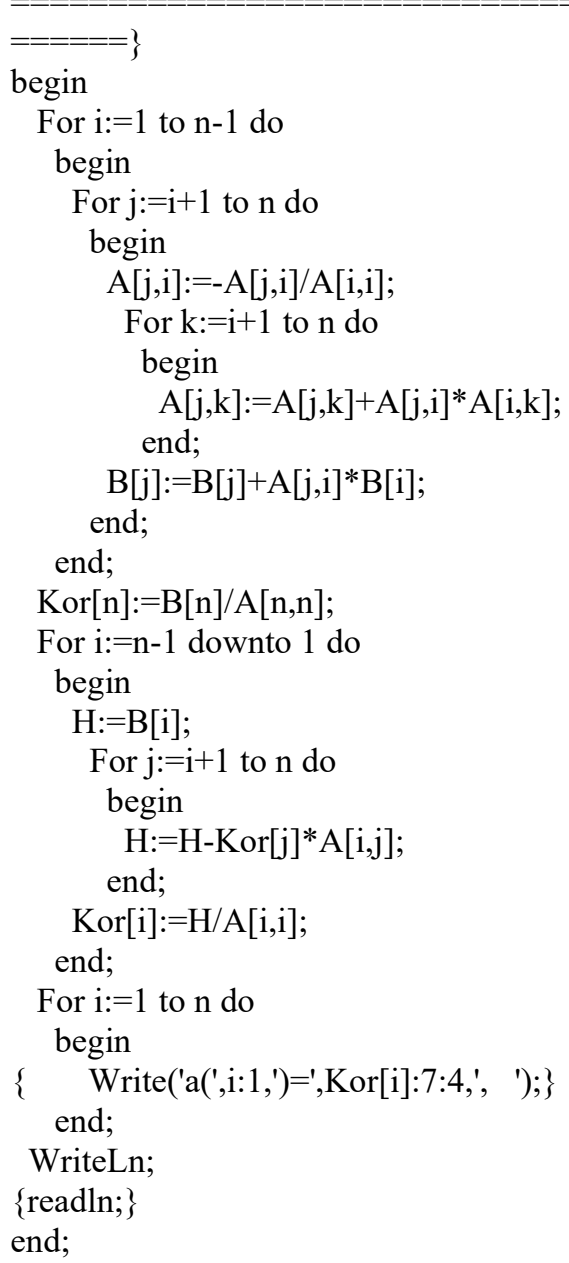

Assumptions adopted when calculating the parameters of equations:

- the size of the sieve hole, equal to 100 , was assumed equal to $99.99999 \mathrm{~mm}$;

- the class with a grain size over "zero" in the calculations was taken as $0.00001 \mathrm{~mm}$.

\section{RESULTS AND DISCUSSION}

As a test example, calculation in Excel of the parameters of 16 approximating functions is shown (Table 1), which were used to describe the total grain-size distribution characteristics of the "Vnoutrenny" seam taken from the study [11]. The size of the sieve holes and the experimental (real) total yield in $(+)$ are presented in columns 1 and 2 of Table. 3.

The calculated values of the parameters $a_{0}, a_{1}$ of the "best" of 16 functions are presented in Table. 2

TABLE 2. PARAMETERS OF THE "BEST" APPROXIMATING FUNCTIONS

\begin{tabular}{|c|c|c|c|c|c|}
\hline $\begin{array}{c}\text { Designation of } \\
\text { function } \\
\text { parameters }\end{array}$ & \multicolumn{5}{|c|}{ Values of function parameters } \\
\cline { 2 - 6 } & $\mathbf{( 6 )}$ & $\mathbf{( 1 0 )}$ & $\mathbf{( 1 3 )}$ & $\mathbf{( 1 5 )}$ & $\mathbf{( 1 6 )}$ \\
\hline$a_{0}$ & 10,89 & 0,069 & 1,174 & 67,684 & 4,4 \\
\hline$a_{1}$ & $-1,084$ & 1,029 & 0,051 & $-5,615$ & $-0,018$ \\
\hline
\end{tabular}

For the indicated parameters of the functions, the calculated values of the yields presented in columns 3-7 of Table 3 are obtained. Let us compare the accuracy of the description of the total characteristic of the size classes of seam "Vnoutrenny" by functions (6), (10), (13), (15) and (16). The quality of the approximations was estimated by the value of the standard deviation between the experimental and calculated values of the total yields of the grain size classes (the last row of Table 3).

TABLE 3. FORECASTING THE AGGREGATE GRAIN-SIZE CHARACTERISTICS OF "VNOUTRENNY" SEAM

\begin{tabular}{|c|c|c|c|c|c|c|}
\hline \multirow{2}{*}{$\begin{array}{c}\text { Screen } \\
\text { size, } \\
\text { mm }\end{array}$} & \multirow{2}{*}{$\begin{array}{c}\text { Total } \\
\text { yield by } \\
(+), \%\end{array}$} & \multicolumn{5}{|c|}{ Total yield values calculated for functions } \\
\hline & & (6) & (10) & (13) & (15) & (16) \\
\hline 1 & 2 & 3 & 4 & 5 & 6 & 7 \\
\hline 100 & 16,2 & 6,9 & 0,0 & 15,9 & 41,8 & 13,5 \\
\hline 50 & 27,1 & 13,6 & 2,1 & 26,9 & 45,7 & 33,1 \\
\hline 25 & 36,6 & 24,9 & 15,1 & 40,8 & 49,6 & 51,9 \\
\hline 13 & 47,8 & 40,3 & 38,1 & 54,4 & 53,3 & 64,5 \\
\hline 6 & 58,2 & 61,0 & 64,7 & 67,6 & 57,6 & 73,1 \\
\hline 3 & 67,4 & 76,8 & 80,8 & 75,4 & 61,5 & 77,2 \\
\hline 1 & 81,8 & 91,6 & 93,3 & 81,6 & 67,7 & 80,0 \\
\hline 0,5 & 93,4 & 95,8 & 96,7 & 83,4 & 71,6 & 80,7 \\
\hline 0,2 & 96,5 & 98,4 & 98,7 & 84,4 & 76,7 & 81,2 \\
\hline 0,1 & 98,6 & 99,2 & 99,4 & 84,8 & 80,6 & 81,3 \\
\hline 0,05 & 99,4 & 99,6 & 99,7 & 85,0 & 84,5 & 81,4 \\
\hline 0 & 100,0 & 100,0 & 100,0 & 85,2 & 132,3 & 81,5 \\
\hline \multicolumn{2}{|c|}{ Standard deviation } & 7,44 & 12,30 & 9,47 & 18,01 & 13,67 \\
\hline
\end{tabular}

It turned out that the best is Pogosov's formula (6), in which the deviation is 7.44 (column 3 of Table 3 ).

To compare the accuracy of the description of the aggregate coal grain-size characteristics by functions of the first degree, a computational experiment was carried out with 500 grain-size distributions of coals of the Kuznetsk basin using a specially developed program Gran16_V.pas.

The results of computational experiments on the description of the aggregate coal size characteristics are shown in Table. 4.

For each aggregate grain-size characteristic, the program calculated the parameters of approximating functions, the values of the total yields were calculated and the best approximation was determined by the smallest value of the standard deviation.

Mathematical models, algorithms and problem-oriented computer programs for modeling the granular and fraction compositions of coals, processes and technologies of gravity enrichment were reported and discussed in 1997, 2016 and 2017 [11-14].

TABLE 4. COMPARISON OF THE ACCURACY OF THE DESCRIPTION OF 500 AGGREGATE COAL GRAIN-SIZE CHARACTERISTICS IN THE KUZNETSK BASIN BY FUNCTIONS OF THE FIRST DEGREE

\begin{tabular}{|c|c|c|c|}
\hline \multicolumn{2}{|c|}{$\begin{array}{c}\text { Numbers and type of } \\
\text { approximating functions }\end{array}$} & $\begin{array}{c}\text { Number of hits } \\
\text { in the top five } \\
\text { approximations }\end{array}$ & $\begin{array}{c}\text { Number of } \\
\text { hits } \\
\text { in the best } \\
\text { approximation }\end{array}$ \\
\hline I & $\begin{array}{l}y=100 a_{0} x^{a 1} /\left(1+a_{0} x^{a 1}\right)- \\
\text { Pogosov's formula }\end{array}$ & 139 & $\mathbf{3}$ \\
\hline$(6)$ & $y=100 /\left(a_{0}+a_{1} x\right)$ & 84 & 15 \\
\hline$(13)$ & $\begin{array}{c}y=100 / \exp \left(a_{0} x^{a 1}\right)-\text { Rosin- } \\
\text { Rammler's }\end{array}$ & 64 & 2 \\
\hline$(10)$ & $y=a_{0}+a_{1} \ln (x)-\operatorname{logarithmic}$ & 26 & 0 \\
\hline$(16)$ & $\begin{array}{c}y=\exp \left(a_{0}+a_{1} x\right)- \\
\operatorname{exponential}\end{array}$ & 23 & 2 \\
\hline
\end{tabular}

The computational experiments established: 
- Out of sixteen first-degree approximations (Table 1), only functions (6), (10), (13), (15) and (16) hit more than ten times in the top five when predicting 500 aggregate coal size characteristics in the Kuznetsk basin (Table 4);

- The best approximation was the function of Pogosov (column 3 of Table 4);

- Rosin-Rammler's formula was in the third place;

- The power function (or Gaudin-Andreev's) has never been among the best;

- to determine the ash content of size classes in the same range a similar program Gran16_A.pas was developed. In the program, the choice of the best approximation is made by the smallest value of the standard deviation between the calculated and experimental values of the ash content of the grain-size classes.

\section{REFERENCES}

[1] A.O. Gates. Trans. AIME, (1916)

[2] A.M. Gaudin. Trans. AIME, (1926)
[3] P. Rosin, E. Rammler. Metall und Erz, (1932)

[4] P. Rosin, E. Rammler. Berichte der keramischen Gesellshaft, (1934)

[5] W. Weibul. Journal of Applied Mechanics, 3 (1951)

[6] Rammler. Neue Bergbautechnik 6, 4 (1976)

[7] D.M. Richter. Neue Bergbautechnik 6, 4 (1976)

[8] P.S. Roller. Journal of Physical Chemistry, 2 (1941)

[9] R. Schuhmann. Mining Technology, 4 (1940)

[10] Daniel D. McCracken, William S. Dorn. Numerical Methods and Fortran Programming, (John Wiley and Sons, Inc., New York, 1965)

[11] V.I. Chudovitsky. Regional APCOM'97 Symposium: The Moscow State Mining University (Publishing Center Moscow, Russia, 1997)

[12] V.I. Chudovitsky. XX International Mineral Processing Congress (Aachen, Germany, 1997)

[13] I. Korolev, V. Udovitsky, XVIII International Coal Preparation Congress (St. Petersburg, Russia, 2016)

[14] V. Udovitsky, V. Kandinsky, A. Begunov, E3S Web of Conferences Vol. 15, 2017

[15] V. Kandinsky, I. Korolev, V. Udovitsky, Key Engineering Materials, Vol. 743, 2017 